\title{
Synchronisation of egg hatching of brown hairstreak (Thecla betulae) and budburst of blackthorn (Prunus spinosa) in a warmer future
}

\author{
H. H. de Vries • S. H. Ens • G. de Graaf • \\ L. Teunissen $\cdot$ R. van der Velde $\cdot$ L. Vogelaar $\cdot$ \\ A. Winterink $\cdot$ M. E. Visser
}

Received: 24 March 2010/Accepted: 9 September 2010/Published online: 25 September 2010

(C) The Author(s) 2010. This article is published with open access at Springerlink.com

\begin{abstract}
Synchronisation of the phenology of insect herbivores and their larval food plant is essential for the herbivores' fitness. The monophagous brown hairstreak (Thecla betulae) lays its eggs during summer, hibernates as an egg, and hatches in April or May in the Netherlands. Its main larval food plant blackthorn (Prunus spinosa) flowers in early spring, just before the leaves appear. As soon as the Blackthorn opens its buds, and this varies with spring temperatures, food becomes available for the brown hairstreak. However, the suitability of the leaves as food for the young caterpillars is expected to decrease rapidly. Therefore, the timing of egg hatch is an important factor for larval growth. This study evaluates food availability for brown hairstreak at different temperatures. Egg hatch and budburst were monitored from 2004 to 2008 at different sites in the Netherlands. Results showed ample food availability at all monitored temperatures and sites but the degree of synchrony varied strongly with spring temperatures. To further study the effect of temperature on synchronisation, an experiment using normal temperatures of a reference year $(T)$ and temperatures of $T+5^{\circ} \mathrm{C}$ was carried out in climate chambers. At $T+5^{\circ} \mathrm{C}$, both budburst and egg hatch took place about 20 days earlier and thus, on average, elevated temperature did not affect synchrony. However, the total period of budburst was 11 days longer, whereas the period of egg hatching was 3 days shorter. The
\end{abstract}

H. H. de Vries $(\varangle) \cdot$ S. H. Ens · G. de Graaf - L. Teunissen ·

R. van der Velde $\cdot$ L. Vogelaar · A. Winterink

Dutch Butterfly Conservation, Mennonietenweg 10,

6700 AM Wageningen, The Netherlands

e-mail: henk.devries@vlinderstichting.nl

M. E. Visser

Netherlands Institute of Ecology (NIOO-KNAW), P.O. Box 40, 6666 ZG Heteren, The Netherlands implications for larval growth by the brown hairstreak under a warmer climate are considered.

Keywords Timing - Thecla betulae - Prunus spinosa . Climate change $\cdot$ Lepidoptera $\cdot$ Herbivory

\section{Introduction}

Egg hatching is a crucial moment in the development of diapausing species (Tauber and Tauber 1976; Harrington et al. 1999). Adverse conditions in the lifetime of individuals are met by going into diapause until more favourable conditions are present. Univoltine species with prolonged periods of diapause are the result of selection against prolonged presence in juvenile or adult life forms. The timing of the irreversible ending of the diapause is an important moment in the life of an individual of such species; young individuals are often vulnerable to starvation, drought or predation. As environments change seasonally from harsh and hostile into friendly and food providing, accurate timing of emergence will ensure a higher chance of survival. Cues indicating these favourable conditions are generally based on day length or temperature, although cues linked more directly to the physiological status of the host plant could theoretically be the best (Harrington et al. 1999). Several papers deal with the importance of timing in lepidopteran species for ending the winter diapause (Dewar and Watt 1992; Buse and Good 1996; Van Dongen et al. 1997; Visser and Holleman 2001; Klemola et al. 2003; Van Asch and Visser 2007; Forkner et al. 2008; Both et al. 2009) showing that mistiming of the ending of diapause can result in high mortality rates. Disruption of the existing synchrony between food plant and butterfly has been observed as a result from climate change 
(Thackeray et al. 2010). For instance, Visser and Holleman (2001) showed that the egg hatch of winter moth (Operophtera brumata) took place 25 days earlier during warm springs, which resulted in first instars being deprived of food due to closed oak buds. Delayed ending of the diapause can also have disadvantages. Late-hatched larvae will be confronted with ample presence of mature leaves, which can have a negative influence on larval growth (Scriber and Slansky 1981; Schroeder 1986; Raupp et al. 1988, Coley et al. 2006; Van Asch et al. 2007). Studies of the influence of temperature on the timing of egg hatch has shown that the effects can be variable and species specific. In some cases, butterfly species normally appear somewhat earlier than budburst (Winter Moth: Visser and Holleman 2001), in other cases, somewhat later (Myers 1992).

In this paper, we investigate the role of temperature on egg hatching in the brown hairstreak (Thecla betulae, Lycaenidae, Lepidoptera) and its possible synchronisation with the budburst of blackthorn (Prunus spinosa). In the Netherlands, $T$. betulae is a rare butterfly, its distribution being restricted to parts of the east and south of the country. The shrub $P$. spinosa is much more widely distributed, partly as a result of the widespread use of this plant in hedgerows and public parks. During recent years, T. betulae has been slowly declining in the Netherlands. This may be due to a disruption of the synchronisation of egg hatching and budburst during recent years. Larvae that hatch too early will be deprived of food, whereas larvae that hatch late can be confronted with food of reduced quality. Unpublished breeding attempts with $T$. betulae indicated low survival rates of first instars when only fed with mature leaves (pers. comm. Groenendijk). Therefore, we hypothesise that accurate timing of egg hatch is essential for creating conditions for optimal growth of first instars of $T$. betulae. Our main question is whether in a warm spring the larvae of $T$. betulae are confronted with closed buds of $P$. spinos $a$ as found for the winter moth by Visser and Holleman (2001). The second question is whether the synchronisation between egg hatch and budburst is similar in different regions.

\section{Materials and methods}

\section{Study organisms}

In the Netherlands and neighbouring countries, brown hairstreak (Thecla betulae) is a rare and red listed species (Van Swaay 2006; Dudler et al. 1999; Maes and Van Dyck 1996). Since 1998, in the Netherlands this species has been monitored annually by egg counting surveys (Fig. 1). The species' recent decline (slope $0.947 \pm 0.0235, P<0.05$ ) has led Dutch Butterfly Conservation to look for possible threats. Adult butterflies are often hidden in tree tops and

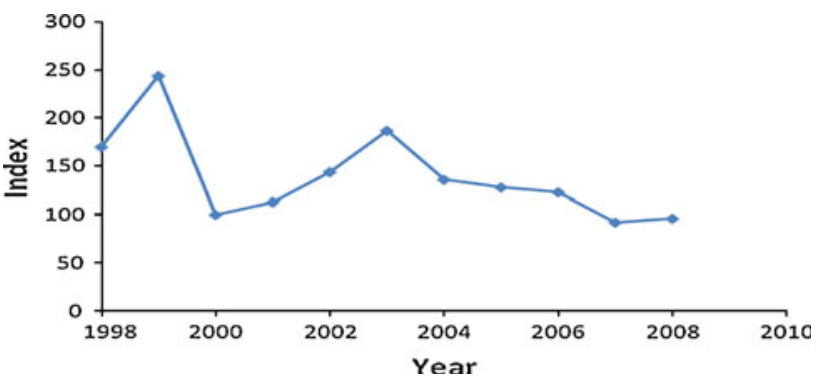

Fig. 1 The results of egg monitoring of T. betulae in the Netherlands (Dutch Butterfly Conservation/Statistics Netherlands). The index (Van Swaay et al. 2002) was fixed at 100 for the year 2000

difficult to observe. The females come down to lay their eggs at observable heights. $P$. spinosa is used for egg deposition and is the main larval food plant during spring and summer. Other Prunus species can be accepted as well (Stefanescu 2000; Bink and Moenen 2004; Koschuh et al. 2005). The distribution of $T$. betulae is limited to the south of the Netherlands (province of Limburg), the edge of the Veluwe, a sandy area (provincie of Gelderland), and some smaller areas in the Northeast (provinces of Overijssel and Drenthe). During summer, from July to September, female butterflies oviposit on young $P$. spinosa branches (Fartmann and Timmermann 2006; Merckx and Berwaerts 2010). The eggs are usually laid singly at heights of between $50 \mathrm{~cm}$ and $2 \mathrm{~m}$. This is in accordance with observations in other countries (Thomas 1974; Fartmann and Timmermann 2006), but Fartmann and Timmermann (2006) concluded from a literature review that there is a slight shift towards a greater oviposition height from Western Europe to Southeast Austria. In the Netherlands, $P$. spinosa is one of the first shrubs to flower, starting in February-March (data www.natuurkalender.nl). Normally, flowering takes place a few weeks before budburst starts. Opening of the buds in April-May gives the young caterpillars the possibility of going inside the newly opened bud and eating the nutritious folded leaves inside. Hatching of the eggs generally starts in April and ends a few weeks later (personal observations). According to Thomas (1974), the first thing the hatched larva does is to search for an open bud and hide inside it. Later, the older instars rest under the leaf, feeding during the evening.

\section{Study areas}

For this study, we observed ten populations of $T$. betulae, eight populations are in town parks, whereas the other two occur in nature reserves. Almost all areas are managed in such a way that the $P$. spinosa shrubs are cut on a regular basis, resulting in presence of young branches for the female T. betulae to deposit their eggs on. Without this kind of management many sites become rapidly unsuitable, 


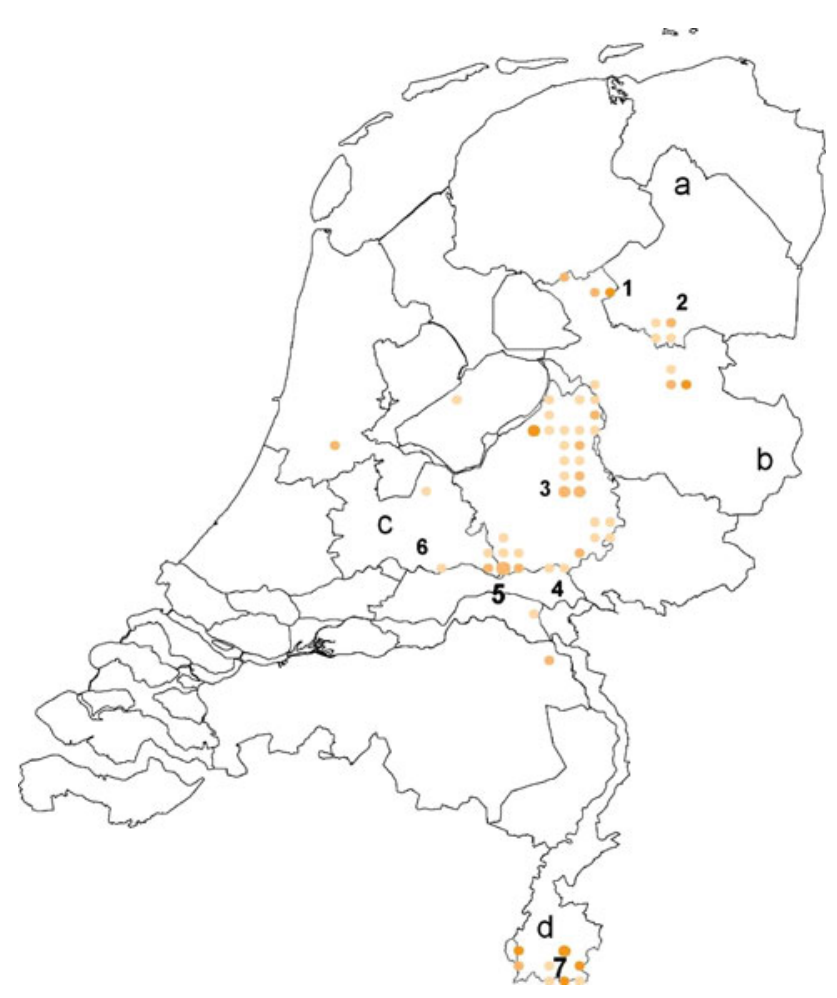

Fig. 2 Eggs were collected at ten locations in seven regions: 1 Steenwijk, 2 Zuidwolde, 3 Apeldoorn (4 locations), 4 Arnhem, 5 Wageningen, 6 Overlangbroek, 7 Zuid-Limburg. Dots represent findings of $T$. betulae in a $5 \mathrm{~km}$ grid (1995-2003), size and coloration indicate relative spatial distribution and number of observations respectively (Bos et al. 2006). Station De Bilt (c) was associated with populations 4, 5 and 6, Station Eelde (a) with 1 and 2, Station Twente (b) with 3, and Station Maastricht $(d)$ with 7

because old branches become overgrown with lichens and algae. The latitudinal positions of the areas were measured using a Dutch kilometre grid (Amersfoort Coordinates). During a 5-year period, we collected data from eggs and plants, monitoring at ten locations in seven regions for 1-5 years (Fig. 2 and Table 1).

\section{Field monitoring}

The eggs are conspicuous white spots on the dark bark from young branches of $P$. spinosa. We looked for eggs during the period from January to March when $P$. spinosa was without leaves, marking the branches with loosely attached coloured ribbons, under the position of the egg. The eggs were examined regularly, when possible twice a week. We distinguished five categories: not rediscovered or missing; parasitized (a lateral hole); predated or damaged; closed; and open, with a characteristic, central hole on top. The timing of egg hatch was calculated solely by using the observed eggs which were first marked and later found open. During the same survey, the availability of food within $20 \mathrm{~cm}$ proximity of the egg was investigated. Presence of closed buds only indicated absence of food, whereas presence of one or more open buds indicated food was available. Each surrounding of an egg got only one score for buds: either all buds were closed or one or more buds were found open. Temperature data were extracted from the KNMI (Royal Netherlands Metereological Institute) database, using meteorological station De Bilt for the butterfly populations in Arnhem, Wageningen and Overlangbroek, Eelde for Zuidwolde and Steenwijk, Twente for Apeldoorn and Maastricht for the region of ZuidLimburg (Fig. 2).

\section{Temperature experiment}

During 2006, we set up a laboratory experiment, with two temperature regimes, one at a standard temperature $(\mathrm{T})$, using outside temperatures of 2004, and another at a higher temperature of $T+5^{\circ} \mathrm{C}$. It started at day 59 (28th of February). Four $P$. spinosa plants and fourteen $T$. betulae eggs were kept at the standard temperature in a climate chamber, simulating minimum, intermediate, and maximum temperatures of the reference year 2004, for six, twelve, and $6 \mathrm{~h}$ respectively. Three times a week the temperatures were adjusted manually to the reference regime, using averages of two or 3 days. $T_{\max }$ of the reference year fluctuated in February 28-May 5th between +2.4 and $+21.5^{\circ} \mathrm{C}, T_{\min }$ between -5.9 and $+12.7^{\circ} \mathrm{C}$. In a second climate chamber, four plants and eleven eggs were kept in a similar, but warmer $\left(T+5^{\circ} \mathrm{C}\right)$ regime. The eggs were collected and installed during 2 days, day 59 and 65 . The plants were delivered by Bronnen, an organisation specialising in indigenous plant material of shrubs and trees. Twice a week, the status of the buds and the hatch of the eggs were monitored using the same method as for field work. After the experiment, the hatched larvae were returned to the sites they had originated from.

\section{Warmth sums}

To measure the influence of temperature on date of egg hatch and budburst warmth sums were calculated using $T_{\max }$ of every day minus a development threshold of $5^{\circ} \mathrm{C}$. From January 1 st until day 100 , the corrected $T_{\max }$ were summed, giving $T_{\text {sum }} 100$ (in degree days). A second parameter for temperature was calculated using low temperatures. For this the numbers of days with frost for the first 100 days were counted for each year, giving Frost100.

\section{Analyses}

The dates of field and laboratory observations were transformed into day numbers, Day 1 being January 1st. Logistic frequency curves were fitted with the dates of egg hatch and budburst and used for further processing. The available data 
Table 1 Investigated regions in different years

\begin{tabular}{|c|c|c|c|c|c|c|c|c|c|c|}
\hline & \multicolumn{2}{|l|}{2004} & \multicolumn{2}{|l|}{2005} & \multicolumn{2}{|l|}{2006} & \multicolumn{2}{|l|}{2007} & \multicolumn{2}{|l|}{2008} \\
\hline & Eggs & Buds & Eggs & Buds & Eggs & Buds $^{a}$ & Eggs & Buds & Eggs & Buds \\
\hline Apeldoorn-H & 24 & 34 & 18 & 21 & & & & & & \\
\hline Apeldoorn-J & 26 & 40 & 24 & 29 & 24 & 9 & & & & \\
\hline Apeldoorn-K & 13 & 43 & 10 & 11 & 21 & 6 & & & & \\
\hline Apeldoorn-Z & 17 & 35 & 17 & 22 & 68 & 59 & & & & \\
\hline Z-Limburg & 62 & 85 & 32 & 87 & 49 & 25 & 46 & & & \\
\hline Overlangbroek & 49 & 65 & 80 & 83 & 83 & 46 & 39 & & 13 & 23 \\
\hline Steenwijk & 89 & 153 & 31 & 50 & 109 & 25 & & & & \\
\hline Zuidwolde & & & & & & & 9 & & & \\
\hline Wageningen & & & 20 & 27 & & & & & & \\
\hline Arnhem & & & & & & & 25 & & & \\
\hline
\end{tabular}

Given are total numbers of hatched eggs and number of observations used for calculating presence of opened buds

${ }^{a}$ Less sample numbers, due to availability of averages per individual plant only

(day numbers) have all in common that the actual moments of opening of buds and eggs are not observed, but estimated from the dates the visits were done. The larger the number of eggs observed, the more accurate the estimates. The data of each location were used to estimate the point at which in a particular year $50 \%$ of the buds as well as $50 \%$ of the eggs were open. This point indicates the moment at which a population of eggs or buds shifts from mostly closed to mostly open. They were derived from interpolation between two points, and in two cases, from extrapolation (Overlangbroek 2004 and Apeldoorn 2006). Two other single dates of locations with $40-60 \%$ open eggs were available and added to the data set (57\% for Zuid-Limburg 2007 and 44\% for Arnhem in 2007).

Using a JMP Statistical Software package (release 5.0.1.2, SAS Institute Inc.) stepwise multiple regressions (Sokal and Rohlf 1981) were calculated with critical p-values smaller than 0.1. Two kinds of models were calculated, type $\mathrm{A}$ and $\mathrm{B}$, with qualitative parameters and quantitative parameters, respectively. The explanatory variables Year (2004-2008) and Region (seven regions) were tested for the response variables egg hatch $(50 \%$ point), budburst (50\% point) and the timing difference between both, resulting in models type A. An additional Effect test gave summary results of Year and Region. Latitude, $T_{\text {sum }} 100$ and Frost100 were tested for the same response variables resulting in models type $\mathrm{B}$.

\section{Results}

Temperature sums and frost

The temperature $\left(T_{\text {sum }} 100\right)$ and frost (Frost100) varied considerable between years, at maximum 383.4 degree days and 44 days with frost respectively, but relative little between regions, at maximum 71.2 degree days and 8 days with frost respectively (Fig. 3a and b). The temperature sum was exceptionally low during the start of 2006, whereas a few months later this year became known for its extreme warm temperatures.

Egg hatch and budburst

Data were collected from 26 year-location combinations for egg hatch and 22 for budburst (Table 1). The egg hatch and budburst in Apeldoorn in 2005 is shown as an example in Fig. 4. Budburst started around day number 74 and egg hatch followed almost 3 weeks later. The results of the monitoring of egg hatch are presented in Fig. 5a. The day numbers at which $50 \%$ of the eggs were estimated to be opened, ranged from 105 to 132 . A multiple regression showed that the day number of egg hatch varied both between Year and Region (Table 2). $T_{\text {sum }} 100$ and Frost 100 both showed significant negative effects on day number of $50 \%$ egg hatch. Figure $5 \mathrm{~b}$ presents the data of budburst of $P$. spinosa and shows that this takes generally place at day number 81-112. A multiple regression (Table 2) showed significant results for Year, but not for Region. $T_{\text {sum }} 100$ showed a significant effect. The timing difference shows considerable variation within Year (Fig. 5c). In 2004, 2005, 2006, and 2008, the timing difference was on average 8, 20, 24 , and 16 days, respectively. The timing difference showed in all cases that the point of $50 \%$ egg hatch was preceded by budburst, although in one case, Overlangbroek 2004 , this is not certain, because it was close to zero and had to be estimated by extrapolation. For this response variable, a multiple regression (Table 2) showed a significant relation with the Year, but not with the Region. The multiple regression gave no significant results for timing difference. 

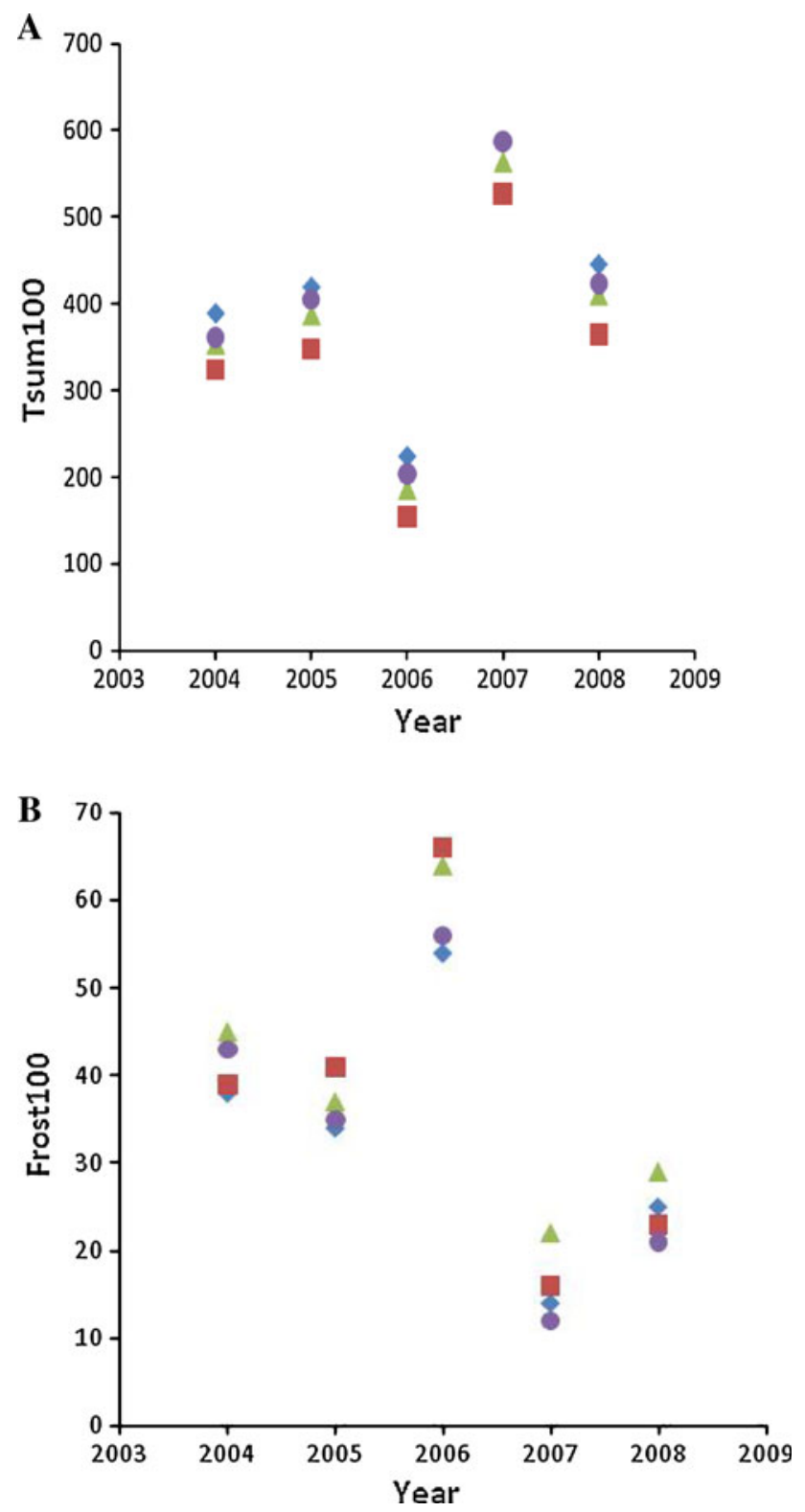

Fig. 3 Temperature sums (in degree days with $5^{\circ} \mathrm{C}$ threshold) from day 1-100 (a) and number of days with frost from day 1-100 (b) at four regions in years 2004-2008: De Bilt (diamonds), Eelde (squares), Twente (triangles), and Maastricht (circles)

\section{Temperature experiment}

Of the fourteen eggs at the normal temperature and the eleven eggs at the high temperature regime 11 and 8 hatched, respectively. We found that as a result of a $5^{\circ} \mathrm{C}$ rise both $50 \%$ points had on average an almost similar shift, being 21 and 19 days for egg hatch and budburst respectively (Fig. 6). Using the two developed models for egg hatch and budburst (Table 2), we predicted a difference between egg hatch and budburst for $\mathrm{T}$ standard and $T+5^{\circ} \mathrm{C}$ of 24 (124 minus 100) and 9 days (94 minus 85)

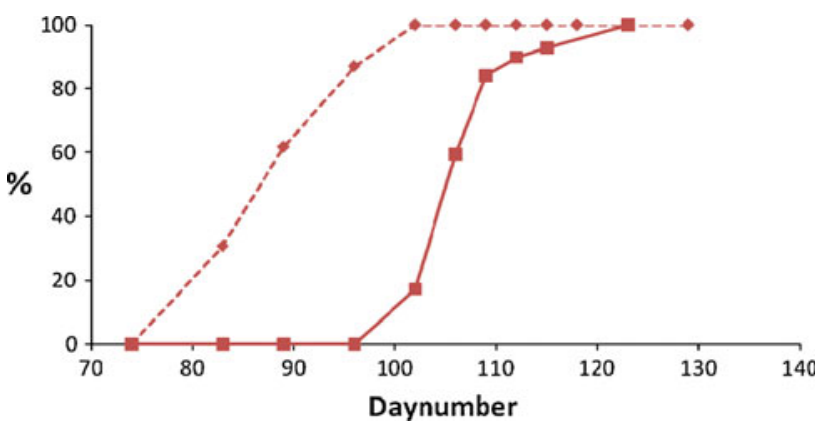

Fig. 4 Cumulative frequency distribution of monitoring results of egg hatch of $T$. betulae (solid line) and budburst of $P$. spinosa (broken line) in Apeldoorn (four sites summed) during 2005

respectively. During the temperature experiment we observed a difference of respectively 9 and 7 days.

The period at which $80 \%$ of the egg hatch took place was in the laboratory experiment under normal conditions 10 days $(n=11)$ and at the $+5^{\circ} \mathrm{C}$ regime 7 days $(n=8$; Table 3$)$. The total period at which $80 \%$ budburst took place was under normal conditions 9 days $(n=162)$ and at the $+5^{\circ} \mathrm{C}$ regime 20 days $(n=202$; Table 3). This results in an egg hatch period being shortened by three days and a budburst period being prolonged by 11 days (Table 3; Fig. 6).

\section{Discussion}

At the start of this investigation, we hypothesised that during some years the egg hatch of some populations of $T$. betulae would be too early. This would perhaps result in days or maybe weeks of starvation for the young larvae, as seen in the Winter Moth (Visser and Holleman 2001; Van Asch 2007). We did not observe this in our study. In three out of 4 years, budburst of $P$. spinosa took place between day 100 and 110, apart from two local exceptions, and in most years, the point of $50 \%$ egg hatch had only minor deviations from day number 110. However, 2006 was an exception, with egg hatch taking place about 20 days later. For the budburst of $P$. spinosa, 2005 was an exceptional year, being much earlier, on between day 80 and 90 in seven out of eight locations. When we compare these results with the data on temperature (Fig. 3) it is clear that the first 100 days in 2006 was much colder compared to the other years, which explains quite well the delay in egg hatch in this particular year. The advancement of budburst during 2005 (day 80-90) cannot be explained by the temperature data. Perhaps calculations with other thresholds (e.g. mean 24-hourly basic temperatures: Wielgolaski 1999) should be used to explain this phenomenon.

The laboratory experiment indicated that 7-9 days difference in timing between egg hatch and budburst is 
Fig. 5 The day of $50 \%$ egg hatch of $T$. betulae during 5 years (graph a, $n=26$ ) and the day of $50 \%$ budburst of $P$. spinosa during 4 years (graph $\mathbf{b}, n=22$ ). Points indicate results from one location. Graph c Timing difference ( $Y$-axis, hatch day minus day of budburst, using $50 \%$ points; $n=22$ ) during investigated years ( $X$-axis). The positive values indicate that the eggs hatched later than buds did burst

normal for this species, which is in accordance with Bink (1992). This result matches with the field observations in the reference year 2004, hence the experiment with standard temperatures mimics field conditions quite well. This difference is somewhat less than that observed during the other 3 years (Fig. 5c: 11-25 days timing difference), and much less than can be calculated with the two available ANOVA-models for the standard temperature (24 days timing difference). At $T+5^{\circ} \mathrm{C}$ the experiment and the ANOVA-models showed comparable results, which might indicate that the model predicts better with high temperature regimes. These predictions are partly based on negative relations between day number of egg hatch and budburst and warmth sum and, for egg hatch, a negative relation with days with frost. The sign of the latter is in accordance with the reduction of threshold warmth sums by frost days found in O. brumata (Visser and Holleman 2001). An accumulation of frost days reduces the warmth sums necessary for hatching, indicating that both species experience warmth sums partly as a relative condition. Under the selected laboratory conditions, a general temperature rise of $5^{\circ} \mathrm{C}$ showed no effect on the average time difference between egg hatch and budburst. However, the egg hatch period shortened and the budburst period prolonged as a result of the increased temperature. This has two consequences. There is a higher chance of ample food being available, but as a result of the absence of a sharp peak in the leaf flush, less chances of a perfect match between egg hatch and budburst. For the first instars of $T$. betulae this asynchrony could well lead to a significantly lower availability of a high quality food source of just opened buds and young leaves. Harrington et al. (1999) concluded that the interval between budburst and the start of larval feeding is an important factor in insect population success. Optimal growth should ensure a lower risk of mortality due to predators (Clancy and Prica 1987) and climate (Andrewartha and Birch 1954; Fordyce and Shapiro 2003) due to a shorter presence of vulnerable small stages. Our experiment indicates that the expected rise of temperature in the future (Loarie et al. 2009) could further reduce population success of $T$. betulae. To confirm this an experiment (e.g. Coley et al. 2006; Van Asch 2007) is needed to evaluate larval growth of $T$. betulae on leaves of different maturity.

Another factor involved in the feeding options of the larvae is their mobility (e.g. Forkner et al. 2008). In this
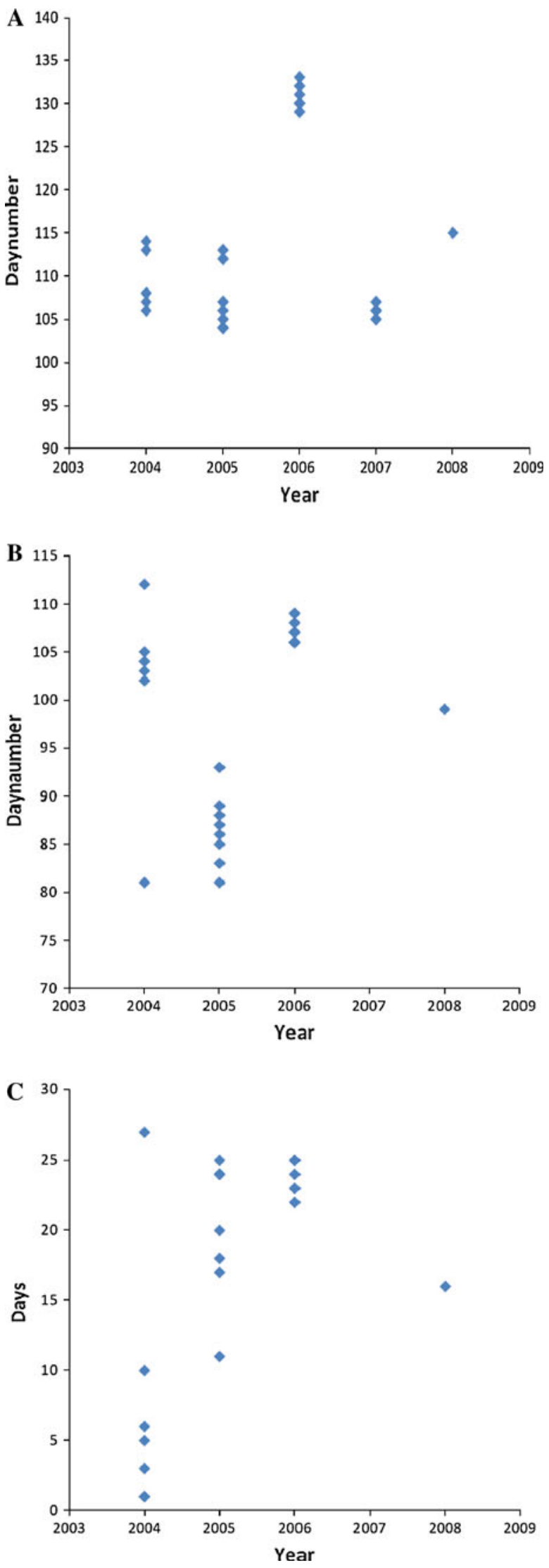
Table 2 Results from testing with ANOVA (calculated stepwise, using a standard least squares ANOVA with $P$-values $<0.1$ )

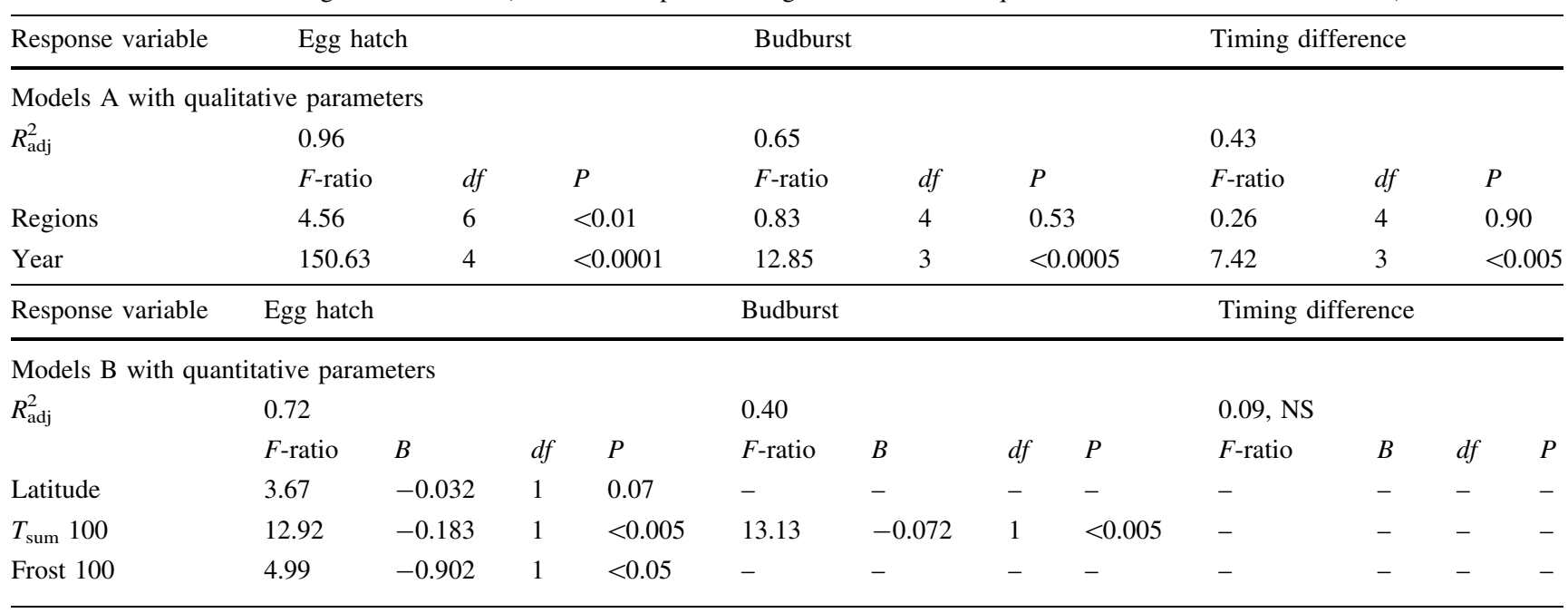

Models A give the explanatory value of Years (4 groups, 5 for timing of eggs) and Regions ( 7 groups) for the three response variables Timing of eggs, Timing of buds, and Timing difference. Models B give for the same response variables the explanatory values of three quantitative variables: Latitude, Warmth sum $T_{\text {sum }} 100$ (degrees above five, summed for each day until day 100), Frost 100 (number of days with frost until day 100). Dashes indicate an unapproved parameter during stepwise building of the model

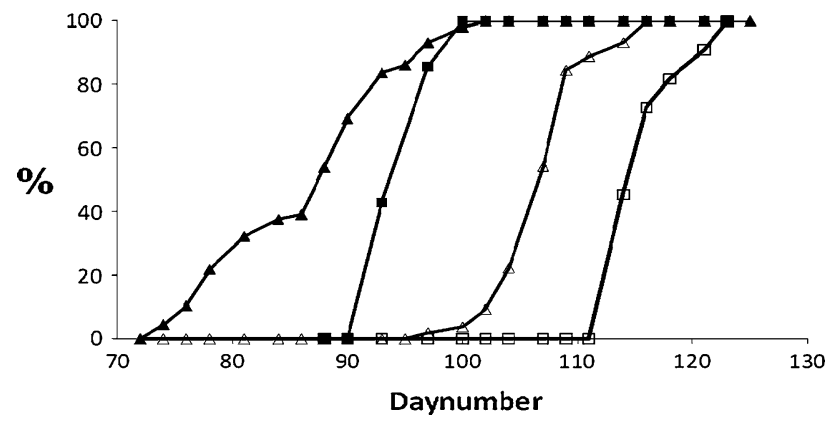

Fig. 6 Results from a laboratory experiment using a standard year (open shapes) and a standard year plus $5^{\circ} \mathrm{C}$ (closed shapes). A cumulative frequency distribution is presented of budburst (triangles) and egg hatch (squares)

study, we estimated the availability of food at $20 \mathrm{~cm}$ distance from the egg, but perhaps young instars are able to search further on the plant for food. According to Thomas (1974), the maximum distance larvae of $T$. betulae move is one meter, but the capability of the tiny newly hatched larvae is surely less. Clearly, a larger action radius could increase the availability and quality of food considerably, but this will depend on the spatial differentiation of budburst events. A wide phenological window caused by the continuous opening of different buds of an individual plant would give both early and late hatched larvae the opportunity to find food. In this way, temperature rise may even lead to unexpected adaptations in dispersal abilities.

The year 2006 was rather extreme in the sense that egg hatch took place on average between 20 and 25 days after budburst in all areas. This was remarkable because the population in the laboratory experiment showed only a little delay in egg hatch at standard temperatures $(50 \%$ hatch was at day 115). It makes it highly likely that in 2006 in situ egg development will have been slowed down by the low outside temperature between the start of the experiment (day 59-65) and the normal time of egg hatch (around day 110). The observed minimum temperatures in the first half of March (day 60-75), several days of five degrees below zero or the high number of days with frost (twenty

Table 3 Estimated 50\% opening date, minima, maxima and ranges of opening date of buds and eggs at a laboratory experiment with two temperatures, standard and $+5^{\circ} \mathrm{C}$

\begin{tabular}{|c|c|c|c|c|c|}
\hline & $\begin{array}{l}\text { Opening date } \\
\text { (10th percentile) }\end{array}$ & $\begin{array}{l}\text { Opening date } \\
\text { (50th percentile) }\end{array}$ & $\begin{array}{l}\text { Opening date } \\
\text { (90th percentile) }\end{array}$ & $\begin{array}{l}\text { Range } \\
\text { (days) }\end{array}$ & $\begin{array}{l}\text { Timing } \\
\text { difference }\end{array}$ \\
\hline T-standard-eggs & 111 & 115 & 121 & 10 & 9 \\
\hline T-standard-buds & 102 & 106 & 111 & 9 & \\
\hline$T+5^{\circ} \mathrm{C}$-eggs & 91 & 94 & 98 & 7 & 7 \\
\hline$T+5^{\circ} \mathrm{C}$-buds & 76 & 87 & 96 & 20 & \\
\hline
\end{tabular}

The timing difference is the difference between the $50 \%$ point of eggs and buds 
out of forty), could be responsible for this phenomenon. Budburst of Blackthorn was not delayed by this late cold period: outside and inside development under normal temperatures were almost the same.

Most of the observed variation in egg hatch, budburst and difference in timing could be explained by the climatic conditions of the year in question. The late hatch in 2006 and the average hatch in 2007 indicate that at the start of the season cold periods are a more effective factor in delaying the date of egg hatch in $T$. betulae than warm periods are in advancing it. It is possible that the population is already adapted to an early spring and has a setback when the season occasionally has a late start. A possible indication of the importance of these cold periods is that the late egg hatch of 2006 was followed by fewer eggs being counted during the national monitoring in 2007 (Fig. 1). Other decreases, as in the years 2000 and 2004, could also have been caused by mismatches or the late appearance of egg hatch. Continuing our observations to obtain a longer time series, could make it possible to get more data about the importance of cold periods for this butterfly. Apart from this aspect, possibly based on recent adaptation to warmer springs, the earlier mentioned lack of possibilities for good timing caused by enlarged phenological windows of budburst should be given attention. Moreover, as we have not seen any caterpillar which was too early, the effect of the maturing of leaves on caterpillar growth is expected to be important in both scenarios. Coley et al. (2006) have already provided good evidence of hampered growth in 85 tropical butterfly species on diets of mature leaves. This still has to be examined for T. betulae. Thus, so far we have shown with the laboratory experiment that the hatching date of this species is well adapted to phenological shifts in budburst during years with increased temperatures.

Acknowledgments We thank the volunteers of Dutch Butterfly Conservation, in particular those of the regions Steenwijk, Apeldoorn and Zuid-Limburg for their kind assistance, the State Forestry Department for their permission to collect eggs, Margriet van Asch for her help with the laboratory experiment, Claire Hengeveld for improving the text, and Michael Wallis de Vries for advice on the analysis. This paper has been kindly supported by a grant from the Erica Foundation in trust of the Prince Bernhard Cultural Foundation.

Open Access This article is distributed under the terms of the Creative Commons Attribution Noncommercial License which permits any noncommercial use, distribution, and reproduction in any medium, provided the original author(s) and source are credited.

\section{References}

Andrewartha HG, Birch LC (1954) The distribution and abundance of animals. University of Chicago Press, Chicago
Bink F (1992) Ecologische Atlas van de Dagvlinders van NoordwestEuropa. Schuyt \& Co, Haarlem

Bink F, Moenen R (2004) Life-history and habitat of the Brown hairstreak Thecla betulae (Lepidoptera: Lycaenidae). Entomol Ber (Amsterdam) 64(4):106-112

Bos F, Bosveld M, Groenendijk D, Van Swaay C, Wynhoff I (2006) De Dagvlinders van Nederland, verspreiding en bescherming (Lepidoptera: Hesperioidea, Papilionidae). Nationaal Natuurhistorisch Museum Naturalis, KNNV \& EIS, Leiden

Both C, Van Asch M, Bijlsma RG, Van den Burg AB, Visser ME (2009) Climate change and unequal phenological changes across four trophic levels: constraints or adaptation? J Anim Ecol 78: $73-83$

Buse ASJ, Good JEG (1996) Synchronization of larval emergence in winter moth (Operophtera brumata L.) and budburst in pedunculate oak (Quercus robur L.) under simulated climate change. Ecol Ent 21:335-343

Clancy KM, Prica PW (1987) Rapid herbivore growth enhances enemy attack: sublethal plant defenses remain a paradox. Ecology 68:733-737

Coley PD, Bateman ML, Kursar TA (2006) The effects of plant quality on caterpillar growth and defense against natural enemies. Oikos 115:219-228

Dewar RC, Watt AD (1992) Predicted changes in the synchrony of larval emergence and budburst under climatic warming. Oecologia 89:557-559

Dudler H, Kinkler H, Lechner R, Retzlaff H, Schmitz W, Schumacher H (1999) Rote Liste der gefährdeten Schmetterlinge (Lepidoptera) in Nordrhein-Westfalen. Landesanstalt für Ökologie. Bodenordnung und Forsten, Landesamt für Agrarordnung, Recklinghausen

Fartmann F, Timmermann K (2006) Where to find the eggs and how to manage the breeding sites of the Brown Hairstreak (Thecla betulae (Linnaeus, 1758)) in Central Europe? Nota Lepid 29(1/2): $117-126$

Fordyce JA, Shapiro AM (2003) Another perspective on the slowgroth/high-mortality hypothesis: chilling effects on swallowtail larvae. Ecology 84:263-268

Forkner RE, Marquis RJ, Lill JT, Le Corff J (2008) Timing is everything? Phenological synchrony and population variability in leaf-chewing herbivores of Quercus. Ecol Ent 33:276-285

Harrington R, Woiwod I, Sparks T (1999) Climate change and trophic interactions. TREE 14:146-150

Klemola T, Ruohomäki K, Tanhuanpää M, Kaitaniemi P (2003) Performance of a spring-feeding moth in relation to time of oviposition and bud-burst phenology of different host species. Ecol Ent 28:319-327

Koschuh A, Savas V, Gepp J (2005) Winter-Eifunde von Zipfelfalterarten (Lepidoptera: Lycaenidae) in Graz und Umland (Steiermark, Österreich). Natursch Landschaftspl 3(2):46-53

Loarie SR, Duffy PB, Hamilton H, Asner GO, Field CB, Ackerly DD (2009) The velocity of climate change. Nature 462:1052-1105

Maes D, Van Dyck H (1996) Een gedocumenteerde Rode Lijst van dagvlinders van Vlaanderen. Instituut voor Natuurbehoud, Brussel

Merckx T, Berwaerts K (2010) What type of hedgerows do Brown hairstreak (Thecla betulae L.) butterflies prefer? Implications for European agricultural landscape conservation. Insect Conserv Diver 3:194-204

Myers JH (1992) Experimental manipulation of the phenology of egg hatch in cyclic populations of tent caterpillars. Can Ent 124: 737-742

Raupp MJ, Werren JH, Sodof CS (1988) Effects of short-term phenological changes in leaf suitability on the survivorship, growth, and development of gypsy moth. Environ Entomol 17: 316-319

Schroeder LA (1986) Changes in leaf quality and growth performance of Lepidopteran larvae. Ecology 67:1628-1636 
Scriber JM, Slansky F Jr (1981) The nutritional ecology of immature insects. Annu Rev Entomol 26:183-211

Sokal RR, Rohlf FJ (1981) Biometry. Freeman and Company, New York

Stefanescu C (2000) New data on the ecology of Thecla betulae in the northeast of the Iberian Peninsula (Lycaenidae). Nota Lepid 23(1):64-70

Tauber MJ, Tauber CA (1976) Insect seasonality: diapause maintenance, termination, and postdiapause development. Annu Rev Entomol 21:81-107

Thackeray SJ, Sparks TH, Frederiksen M, Burthe S, Bacon PJ, Bell JR, Botham MS, Brereton TM, Bright PW, Carvalho L, CluttonBrock T, Dawson A, Edwards M, Elliott JM, Harrington R, Johns D, Jones ID, Jones JT, Leech DI, Roy DB, Scott WA, Smith M, Smithers RJ, Winfield IJ, Wanless S (2010) Trophic level asynchrony in rates of phenological change for marine, freshwater and terrestrial environments. Glob Change Biol. doi: 10.1111/j.1365-2486.2010.02165.x

Thomas JA (1974) Factors influencing the numbers and distribution of the Brown Hairstreak, Thecla betulae L. (Lepidoptera, Lycaenidae) and the Black Hairstreak, Strymonidia pruni L. (Lepidoptera, Lycaenidae). Phd thesis, University Leicester

Van Asch M (2007) Seasonal synchronization between trophic levels under climate change. $\mathrm{PhD}$ thesis, Rijksuniversiteit Groningen
Van Asch M, Visser ME (2007) Phenology of forest caterpillars and their host trees: the importance of synchrony. Annu Rev Entomol 52:37-55

Van Asch M, Van Tienderen PH, Holleman LJM, Visser ME (2007) Predicting adaptation of phenology in response to climate change, an insect herbivore example. Glob Change Biol 13: $1596-1604$

Van Dongen S, Backeljau T, Matthysen E, Dhondt AA (1997) Synchronization of hatching date with budburst of individual host trees (Quercus robur) in the winter moth (Operophtera brumata L.) and its fitness consequences. J Anim Ecol 66:113-121

Van Swaay CAM (2006) Basisrapport Rode lijst dagvlinders. Rapport VS2006.002 De Vlinderstichting, Wageningen

Van Swaay CAM, Plate CL, Van Strien A (2002) Monitoring butterflies in the Netherlands: how to get unbiased indices. Proc Exp Appl Entomol 13:21-27

Visser ME, Holleman JM (2001) Warmer springs disrupt the synchrony of oak and winter moth phenology. Proc R Soc Lond B 268:289-294

Wielgolaski FE (1999) Starting dates and basic temperatures in phenological observations of plants. Int $\mathrm{J}$ Biometeorol 42: $158-168$ 